THE INTERNATIONAL

REVIEW OF RESEARCH IN

OPEN AND DISTANCE LEARNING

\title{
Applying Constructionist Principles to Online Teacher Professional Development
}
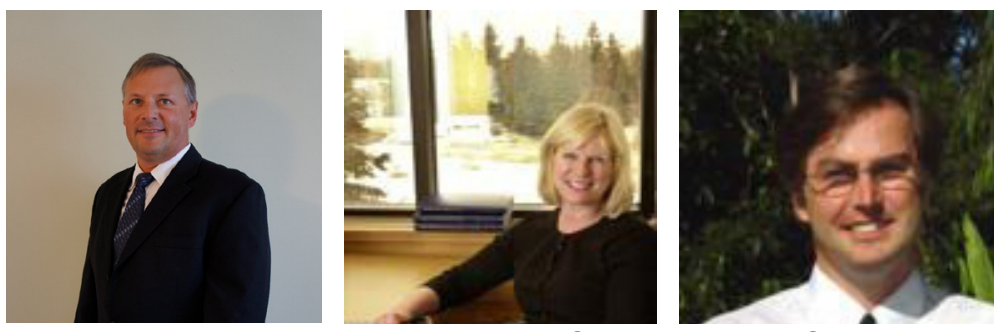

Nathaniel Ostashewski and Susan Moisey Athabasca University, Canada

Doug Reid

Wayfarer Education Group, Canada

\section{Abstract}

This report explores the first iteration of a teacher professional development courselet grounded in constructionist theory and activities. This online teacher professional development (oTPD) courselet provided opportunities for teachers to engage in just-in-time, ongoing TPD within a social networking site for educators. The topic of the oTPD was Robotics and Hands-on Activities in the Classroom. The courselet was designed for teachers who are interested in integrating constructionist pedagogies into their practice. Key findings of the first delivery of the oTPD courselet point to a need for flexible access, sharing of resources, and support for constructionist pedagogical activities as a PD value for participants. Findings further support the potential for an ongoing online community of practice around robotics in the classroom. The approach taken in this oTPD courselet of study continues to inform a model of oTPD delivery within a social-networking-enabled environment.

Keywords: Constructionist; robotics; oTPD; teacher professional development; courselet

\section{Introduction}

Tell me, and I will forget.

Show me, and I may remember.

Involve me, and I will understand.

Confucius, circa 450 B.C. 
As the Information Age continues to evolve, digital media literacy continues to rise in importance as a key skill in almost every profession (Johnson, Levine, Smith, \& Stone, 2010). Social media technologies are becoming pervasive in work environments, and knowledge of their affordances, applications, and uses is becoming increasingly important. In classrooms, new media technologies underscore every part of students' lives as tools for social networking, online collaboration, and media sharing are all rapidly maturing and becoming integrated in education and recreation activities (Hovorka \& Rees, 2009).

Educators are charged with the task of creating learning activities that integrate these new technologies, although few have any formal training in digital and social media (Whitehouse, Reynolds, \& Caperton, 2009). This problem is further compounded by the fact that new information technologies and processes are emerging faster than they can be integrated into course material and textbooks, so even newly graduated teachers are often sorely behind in their knowledge of the technologies of which they are expected to be skilled practitioners. As a result, teacher professional development (TPD) that focuses on the integration of these new technologies into teaching practice is critically needed. Additionally, access to timely, ongoing, and relevant TPD opportunities to meet these kinds of needs is a persistent challenge. Online teacher professional development (oTPD) has the potential of fulfilling these needs in current educational situations (Dede, Ketelhut, Whitehouse, Breit, \& McCloskey, 2009; Herrington, Herrington, Hoban, \& Reid, 2009; Vrasidas \& Glass, 2004). The literature has identified a critical need for research into accessible and highquality oTPD implementations (Dede et al., 2009; Sprague, 2006). Despite the potential of oTPD, however, little research is being conducted to explore its implementation and effectiveness (Borko, Whitcomb, \& Liston, 2009; Whitehouse, Breit, McCloskey, Ketelhut, \& Dede, 2006). The use of oTPD and Web 2.o technologies, which require a demand-pull rather than a supply-push teaching and learning approach (Whitehouse et al., 2009), may in fact meet constructionist online learning challenges and needs.

Desimone (2009) reports a recent consensus on the critical features of TPD that lead to increased knowledge and skills and to improved practice. These features include content focus, active learning, coherence, duration, and collective participation. Of these features, content focus and how students learn that content were considered the most influential for teacher professional development success. The oTPD implementation described in this paper encompassed all these essential features.

The research reported in this paper is part of an ongoing design-based research (DBR) program centered on the development, design, and evaluation of courselets. A courselet is a module of oTPD delivery using content-focused instructional packages and the creation of learning artifacts to demonstrate learning, delivered within a social networking site (Ostashewski, 2010; Ostashewski \& Reid, 2010). Online social networking is a new way for teachers to access PD, and courselets have the potential to provide asynchronous, synchronous, or blended learning opportunities that are inexpensive and scalable and provide new types of TPD learning opportunities (Whitehouse, 2010). This research into oTPD seeks new ways to meet teachers' learning needs, to identify opportunities for developing online communities to support learning (Oliver \& Brook, 2002), and to extend the knowledge of 
the field of oTPD in order to create effective models for PD in the $21^{\text {st }}$-century.

The advantages of utilizing an online social networking framework as a delivery platform for oTPD are threefold. First, the online delivery platform supports and encourages teachers to learn together, while allowing them to retain control over their time, space, presence, activity level, identity, and relationships (Anderson, 2006). Increasingly, demands on teachers' time and teachers' lack of control over their PD activities result in one-time PD workshop sessions that are well documented to have little transfer to classroom practice (Borko, 2004). However, the delivery of PD through online social networking allows teachers to control their access and participation in relevant activities.

Second, it promotes the development of a network of relationships, which teachers can access to support their classroom teaching practices beyond their more formal oTPD activities. This is an expansion of a more traditional network that can exist within a school or school district. This online network of teachers does not need a bricks-and-mortar connection; it uses relevant online tools for communication and connection.

Third, the delivery of professional development via a social networking site provides teachers with firsthand experiential learning about online technologies, using tools such as blogs, forums, and video and file sharing. The opportunity to actively engage with these online tools for the purpose of creating online resources and artifacts and then sharing them with other teachers to support their learning (an example of constructionist pedagogy in practice) provides teachers with an authentic experience of how online technologies can be used in their own classrooms.

\section{The Study}

This paper reports on a single iteration of an ongoing DBR study focusing on the development and delivery of oTPD within a social networking site. DBR is a constructive activity that allows researchers to produce and add to the foundation of educational technology theory and may contribute more than other types of research to this field (Wang \& Hannafin, 2003). An understanding of the outcomes of design-based research can be found by exploring a key component of the methodology. This key component is an iterative development-delivery- evaluation-redesign cycle. The cycle is the process by which DBR is able to broadly explore the nature of a learning innovation and the complex system in which it occurs. A design-based research program goes beyond perfecting a specific product or artifact to generate a model of a successful innovation supported by design and implementation principles (Design-based Research Collective, 2003).

In this research study, the constructive activity of building the environment, structure, and processes needed to deliver oTPD is grounded by both the literature and the ongoing evaluations that occur as part of the development and delivery activities. DBR blends empirical educational research with theory-driven design of educational environments and is an important research methodology for detailing when, why, and how innovative educational solutions work in practice (Design-based Research Collective, 2003). It is this type of research 
process that we believe will help educators to understand the relationships among theory, designed innovations, and practice.

\section{The Context}

In 2009, an online educator community, www.2Learn2Gether.ca (2Learn.ca Education Society, n.d.), was established by the 2Learn.ca Education Society in order to provide support for Alberta educators in the form of a collaborative online environment. The community was based on social networking software customized to provide members with tools commonly found in social media sites like Facebook and Ning or learner management systems like Moodle. Participant interactions in the online community involved user-created groups and forums, personal and group blogs, event calendars, and member messages. Learning opportunities included participation in activities to support in-class events, access to professional development videos, file uploading and sharing, and oTPD courselets. The latter were similar to traditional online courses, but the social networking tools inherent in the environment were used throughout the structured educational offering. Courselets were designed to involve 10-15 hours over 6-8 weeks of learner engagement with the material and interactions with other participants and the facilitators. This amount of learner engagement differs remarkably from the 39 hours over 12-13 weeks required in a university course and 6-8 hours in a typical single-event, face-to-face teacher professional development session.

A particular courselet titled "Robotics and Hands-on Activities in the Classroom" was intended to provide teachers with an exemplar in two distinct forms: as a group of learning activities demonstrating constructionist pedagogy in action (i.e., the instructional design of the courselet was based on constructionism) and through the instructional materials themselves. The courselet materials presented LEGO robotics activities structured for a constructionist environment, including the presentation of the content, the building of robots, and the manner of classroom implementation. In other words, not only did the participating teachers experience the constructionist approach, but they also learned about constructionist pedagogy and how to incorporate it into their own classroom teaching practices. This result is in line with the findings of several studies (Alimisis, 2008; Alimisis et al., 2007; Bers, Ponte, Juelich, Viera, \& Schenker, 2002; Stager, 2009), which showed that engaging teachers in robotics training activities resulted in the integration of computerbased robotics into the classroom and the transformation of classroom environments toward constructivist learning. The activities in this Robotics courselet engaged teachers with the constructionist literature and encouraged them to discuss and evaluate content-focused online resources, as well as to participate in constructionist activities by sharing their reflections on the challenges of applying a constructionist approach in the classroom. The final courselet product was an online lesson plan utilizing the discussions and constructions of these TPD activities. Seen through the lens of constructionist theory and emerging models of instructional design, the Robotics courselet provided an opportunity for participants to experience and reflect on a new strategy to add to their "instructional toolkit" or teaching repertoire. Within the constructionist paradigm of the Robotics courselet, participants formed new relationships with knowledge, something that Kafai and Resnick (1996) argue 
is as important as forming new representations of knowledge.

The theoretical framework and literature that informed the design of the Robotics courselet activities and content is based on Seymour Papert's (1999) constructionism learning theory. Hands-on learning, learning by doing, and learning through constructive play or gaming are some descriptions of the application of constructionism and provide insight into the use of this teaching and learning theory. In this setting, the application of constructionist learning theory is represented through the act of constructing an artifact as this is a significant step in the knowledge representation process. These acts of construction can be virtual actions, such as the manipulation of software, or real actions, such as the physical manipulations needed in order to create an artifact. The creation of this artifact, or product, allows the learner to develop a deeper understanding of the concept being studied. Papert's theory of constructionism arose from learning associated with digital media and computer-based technologies and is more pragmatic and situated than Piaget's theory of constructivism.

According to constructionist theory, tools, digital media, artifact construction, and reflective discourse on the artifact are the basis of new knowledge construction. Similarly, the social media web provides a framework where learners are equipped with a constantly expanding array of online digital tools, allowing them to construct and share their digital artifacts instantly with others around the world, a feat that Papert and others probably considered impossible 30 years ago.

A distinct set of characteristics of effective teacher professional development (Desimone, 2009; Schwille et al., 2007) was used in the development of the courselet. Schwille et al. (2007) identify two key dimensions of effective TPD: core features and core structures. The core features focus on content, active learning, and coherence. The core structures are duration, form, and participation. Desimone (2009) affirmed that recent research reflects a consensus about some of the characteristics critical to effective TPD that increases student achievement: content focus, active learning, coherence, duration, and collective participation. The development of the courselet ensured that these characteristics were present in its oTPD implementation.

One of the challenges of oTPD is to provide active learning opportunities tied to curricular goals that engage learners in student-student interactions. Online active learning can take the form of wikis, video productions, or collaborative projects. Engaging online learners in the construction of a reflective blog within the social setting of the World Wide Web is a constructivist learning activity. However, immersing students in RSS and blogging experiences as a component of online learning extends their levels of involvement and reflection as the act of publishing about their thinking "ups the ante" and results in a constructionist learning activity (Toledo, 2007). Additionally, constructionist online activities provide the ability to scaffold learning, a constant challenge for accommodating the diverse capabilities of online and distance learners. In summary, constructionism has the potential to elicit meaningful active learning artifacts to support and meet the needs of networked connectionist distance education (Papert, 1992; Siemens, 2005). 
Teacher professional development activities with constructionist design principles have the potential to be highly effective, providing teachers with an exemplar of constructionist activities to allow them guidance and support in the construction of meaningful, applicable teaching artifacts. The literature review found 10 studies that met this criterion: Alimisis, 2008; Alimisis et al., 2007; Bers et al., 2002; Chambers \& Carbonaro, 2003; Helps, 2007; Koehler \& Mishra, 2005a; Koehler \& Mishra, 2005b; Richards, 2009; Stager, 2009; and Whitehouse et al., 2009. These studies support the approach of engaging teachers in the design of a technology implementation plan or lesson plan in order to increase their understanding and confidence with constructivist learning. Programs such as these assist teachers in designing effective technology activities for their classroom. The goal of the teacher professional development reported in this paper is ultimately for students to be engaged in constructionist activities through their teachers' authentic engagement in and construction of new knowledge.

\section{Courselets}

The implementation of constructionist principles in teacher professional development is part of an ongoing design-based program of research centered on the development, design, and evaluation of courselets. This courselet involved 10-15 hours of teacher interaction and was delivered via a Web site (Ostashewski, 2010; Ostashewski \& Reid, 2010). The courselet structure provided learning opportunities that are based on constructionist principles and that are inexpensive and scalable when delivered via an online social networking site.

The online learning experiences designed into the courselet were valuable to teachers in numerous ways. They provided an opportunity to use new communication technology tools to learn online, as well as structured activities for teachers to create artifacts to support their learning. The courselet also gave access to specialized TPD at a distance. Using online forums, blogs, videos, and other social media embedded in the oTPD delivery provided numerous opportunities for teacher-centered online learning experiences.

Building on these design principles, and taking into consideration the lessons learned from ongoing TPD delivered on the 2Learn2Gether.ca social networking site, an oTPD courselet model evolved. Seven design principles have been developed based on theoretical, pedagogical, and practical considerations of courselet delivery. These seven design principles are presented below with a brief description of the corresponding courselet learning activities .

1. Design learning relevant to teacher professional practice.

a. Ensure that the resources and the learning experiences are relevant to the learner.

b. Situate learning in current teaching challenges.

c. Design the learning activities so that they lead to an outcome that can be applied in teacher professional practice. 
2. Provide easy teacher access, designing for flexibility and ongoing support.

a. Provide short, focused courselets addressing specific technology issues.

b. Design activities to allow flexibility and teacher choice in activities.

3. Provide theoretically and pedagogically sound activities.

a. Provide a rich array of resources to support learners' individual needs.

b. Support the teacher in linking conceptual understanding and practical application.

c. Provide activities that engage teachers with the content area using technology tools.

4. Provide support for learners with varied experience levels.

a.Provide a scaffolded educational environment that supports learning and reflection for a variety of learners.

b. Scaffold teacher opportunities for inquiry, engagement, and reflection.

c. Provide pre-courselet materials (in a variety of formats) to support tool use for new social networking site users.

5. Provide authentic opportunities for networked learning skill development.

a. Provide external resources as primary content.

b. Design activities to utilize blog and forum contributions.

c. Provide online lesson plan tools.

6. Support sharing and discourse among learners.

a. Design activities that focus on reflective practice.

b. Design activities that lead to meaningful learner discourse.

c. Provide opportunities for teacher collaboration.

7. Support learning connections to the broader networked community.

a. Utilize information sources external to the group.

b. Identify and share other potential sources of content information.

By developing oTPD offerings based on these design principles, we are providing teachers with meaningful and valuable PD that is quite different from other types of TPD. White- 
house (2010) states-and we concur-that the networked learning environment blurs the meaning of "present" as teachers work across time and location, bringing new experiences of learning from social networking sites. This is therefore the potential that our oTPD research continues to strive for: to create opportunities for new teacher learning experiences online.

\section{Delivery}

In addition to the design principles of the oTPD courselet, it is helpful to understand the social media technologies used in the oTPD implementations as the model was honed. The oTPD courselet structure provided the following elements for teacher participants:

- courselet overview, which gave a short description of the courselet goals and outcomes of participation;

- courselet activity guide, which presented links and participant expectations for each week of courselet activities; instructions and links to external articles and Web sites, as well as internal courselet videos, were described in each of the weekly activity guides;

- group blogs, which allowed participants to use the threaded comments to track their own professional growth and challenges during the oTPD activities;

- personal blogs, which were used in some courselets to allow participants to make private or public posts within the social networking site, while not being confined to the group space;

- discussion forum, which was used to initiate discussions to support the TPD activities that the facilitator moderated ;

- embedded videos, which included instructional segments on tools found within the courselet, such as "how to post a blog," as well as external content exemplars found on YouTube;

- event calendar, which listed dates or suggested start times for activities within the courselet;

- external social bookmarking site, which was used to provide a collection of links around the specific topic being explored in the courselet;

- file-sharing folder, which allowed documents, such as additional "how to" guides, to be readily available for teacher participants; as well, the file-sharing capability made it possible for participants to upload images that demonstrated completed activities and to share documents such as lesson plans; and

- list of courselet participants, which provided easy access to profiles of courselet participants to all participants. 
The "Robotics and Hands-on Activities in the Classroom" oTPD courselet was based on a constructionist design that provided learner engagement with the four tenets of constructionism (Bers et al., 2002). Numerous participants reported that this was their first TPD experience with LEGO robotics and that the experience provided a much-needed technology support activity for their teaching practice. One early career teacher indicated that he was assigned to a teaching position where LEGO robotics was the focus and that the oTPD courselet provided critically needed resources, networking, and classroom applications that were not made available to him any other way. The teacher reported that his students would have had far fewer opportunities to explore LEGO robotics activities without the timely and flexible access that the oTPD courselet provided.

The weekly activity guide presented links and participant expectations for each week of the "Robotics and Hands-on Activities in the Classroom" courselet activities. Instructions and links to external articles and Web sites, as well as internal courselet videos, were described in each of the weekly activity guides. Courselet videos included instructional segments on tools used within the courselet as well as external LEGO robot exemplars found on YouTube. Weekly discussions were initiated by the instructor in the courselet discussion forum, and the instructor moderated ongoing threads that supported the activities of each week. The file-sharing folder allowed the posting of PDF documents, including step-by-step "how to" guides. As well, the file-sharing folder made it possible for participants to upload images demonstrating a completed LEGO robot constructed as part of one week's activities. The group blog, which allowed participants to post either an entry or threaded comments connected to an entry, was used by the instructor to have the participants track their own professional growth and challenges during the courselet activities. Teachers commented that the value of both the discussions and the blog postings appears to revolve around the sharing of resources and teaching strategies using these resources. The social networking framework in which the courselet was delivered, by default, lends itself to information sharing, contributing to the overall value to teachers of this type of oTPD delivery.

Following the constructionist pedagogy, there was evidence in the participant interactions that the Robotics courselet allowed teachers to form new relationships through the social networking environment and provided timely access and resources to support new classroom activities.

\section{Findings}

Findings of the first delivery of the "Robotics and Hands-on Activities in the Classroom" OTPD courselet indicate considerable value for participants in the manner in which the oTPD experience was delivered, the social networking learning experience, and the content of the courselet. The importance of flexibility of access to the courselet materials was a key finding. As part of the courselet, participants were directed to online resources and provided with the opportunity to dialogue with experienced LEGO robotics teachers on a flexible schedule over a period of eight weeks. Teachers reported that the flexibility of the courselet timeline and activities was a very important success factor as they often struggled 
with finding time to access PD activities during teaching.

The second key finding was that the utilization of a social networking site for the delivery of the courselet supported TPD learning in a new manner. Participant feedback regarding the delivery of the courselet within a social networking site indicated that while some participants were familiar with the Web 2.0 toolset and used it daily in their teaching practice, it was new to other teachers and required time to learn how to navigate and use. Both groups of teachers reported that there was value in the social network site delivery. This finding highlights the value of providing oTPD activities in a social networking site as the authentic online learning opportunities themselves are a form of oTPD. Teachers reported learning about the use of online learning tools as a result of participating in the courselet, a significant courselet outcome. As Borko et al. (2009) indicate, teachers need these kinds of oTPD opportunities to be able to use these kinds of technology in the delivery of instruction to their students.

The third key finding was that the courselet effectively supported TPD learning about the LEGO robotics content. Outlining objectives and scaffolding learning for teachers by providing all of the materials at the beginning of the courselet was reported to assist teachers in knowing how to manage their progress through the activities. Instructional video segments and PDF materials supporting interactions, such as blog posting or lesson plan development, provided participants with needed asynchronous support. Access to new resources identified in the materials and in forum discussions was reported as very valuable for classroom application of LEGO activities. Networking with other teachers who were also integrating LEGO robotic activities and sharing experiences within this community allowed teachers to develop relationships that continued beyond the courselet activities. This networking with an extended LEGO robotics community was evidenced in two ways: Teacher participants asked to have continued access to the courselet artifacts and discussion space, and several participants volunteered to be involved in the 2010 FIRST Lego League (FLL, see http://www.firstlegoleague.org/) international competition as coaches or volunteers, due in part to their courselet participation.

\section{Conclusion}

In conclusion, the Robotics courselet provided an opportunity for teacher participants to experience, reflect, and plan for the implementation of a "new" constructionist pedagogical strategy in their instructional toolkit. By providing teachers with exposure to and experience with constructing robots, using guided reflective blogs, sharing resources and classroom implementation ideas through forum postings, and constructing a digital artifact (online lesson plan), the constructionist TPD design was demonstrated to be an effective method of oTPD. As well, the authentic learning opportunities afforded by the social networking site delivery format provided valuable technology-related skills and knowledge. Findings support the development of a new online teacher community that has the potential to provide ongoing access to resources and expertise. The delivery of technology oTPD activities provided within a social networking software community holds promise for the further support 
of LEGO robotics technologies in the classroom with the potential of sustaining a mature robotics online teacher community. 


\section{References}

2Learn.ca Education Society. (n.d.). The 2Learn2Gether.ca educator community. Available at http://www.2Learn2Gether.ca

Alimisis, D. (2008). Designing robotics-enhanced constructivist training for science and technology teachers: The TERECoP project. In J. Luca \& E. Weippl (Eds.), Proceedings of the World Conference on Educational Multimedia, Hypermedia and Telecommunications 2008 (pp. 288-293). Chesapeake, VA: AACE.

Alimisis, D., Moro, M., Arlegui, J., Pina, A., Frangou, S., \& Papanikolaou, K. (2007). Robotics and constructivism in education: The TERECoP project. In Ivan Kalas (Ed.), EuroLogo 2007: 40 Years of Influence on Education-Proceedings of the 11th European Logo Conference. Bratislava, Slovakia: Comenius University.

Anderson, T. (2006). Higher education evolution: Individual freedom afforded by educational social software. In M. Beaudoin (Ed.), Perspectives on the future of higher education in the digital age (pp. 77-90). NY: Nova Science.

Bers, M. U., Ponte, I., Juelich, K., Viera, A., \& Schenker, J. (2002). Teachers as designers: Integrating robotics in early childhood education. Information Technology in Childhood Education Annual, 2002(1), 123-145.

Borko, H. (2004). Professional development and teacher learning: Mapping the terrain. Educational Researcher, 33(8), 3-15.

Borko, H., Whitcomb, J., \& Liston, D. (2009). Wicked problems and other thoughts on issues of technology and teacher learning. Journal of Teacher Education, 6o(1), 3-7.

Chambers, J., \& Carbonaro, M. (2003). Designing, developing, and implementing a course on LEGO robotics for technology teacher education. Journal of Technology and Teacher Education, 11(2), 209-241.

Dede, C., Ketelhut, D., Whitehouse, P., Breit, L., \& McCloskey, E. (2009). A research agenda for online teacher professional development. Journal of Teacher Education, 6o(1), $8-19$.

Desimone, L. (2009). Improving impact studies of teachers' professional development: Toward better conceptualizations and measures. Educational Researcher, 38(3), 181-199.

Design-based Research Collective. (2003). Design-based research: An emerging paradigm for educational inquiry. Educational Researcher, 32(1), 5-8.

Helps, R. (2007). Dancing on quicksand gracefully: Instructional design for rapidly evolving technology courses. In B. Sweeney, D. Feinstein, \& J. Ekstrom (Eds.), Proceedings of the 8th ACM SIGITE Conference on Information Technology Education 
(pp. 1-8). Destin, FL.

Herrington, A., Herrington, J., Hoban, G., \& Reid, D. (2009). Transfer of online professional learning to teachers' classroom practice. Journal of Interactive Learning Research, 2O(2), 189-213.

Hovorka, D., \& Rees, M. (2009). Active collaboration learning environments: The class of Web 2.o. In H. Scheepers \& M. Davern (Eds.), Proceedings of the 2oth Australasian Conference on Information Systems: ACIS 2009 (pp. 550-561). Melbourne, AU.

Johnson, L., Levine, A., Smith, R., \& Stone, S. (2010). The 2010 Horizon report. Retrieved from http://www.nmc.org/pdf/2010-Horizon-Report.pdf

Kafai, Y., \& Resnick, M. (Eds.) (1996). Constructionism in practice. NY: Laurence Erlbaum Associates.

Koehler, J., \& Mishra, P. (2005a). Teachers learning technology by design. Journal of Computing in Teacher Education, 21(3), 94-101.

Koehler, J., \& Mishra, P. (2005b). What happens when teachers design educational technology? The development of technological pedagogical content knowledge. Journal of Educational Computing Research, 32(2), 131-152.

Oliver, R., \& Brook, C. (2002). Supporting the development of learning communities in online settings. In P. Barker \& S. Rebelsky (Eds.), Proceedings of the World Conference on Educational Multimedia, Hypermedia and Telecommunications 2002 (pp. 192-197). Chesapeake, VA: AACE.

Ostashewski, N. (2010). Online technology teacher professional development courselets: Design and development. In D. Gibson \& B. Dodge (Eds.), Proceedings of the Society for Information Technology \& Teacher Education International Conference 2010 (pp. 2329-2334). Chesapeake, VA: AACE.

Ostashewski, N., \& Reid, D. (2010). Online teacher professional development: Redesign and delivery of a technological pedagogical courselet within a social networking site. In Proceedings of the World Conference on Educational Multimedia, Hypermedia and Telecommunications 2010 (pp. 1111-1116). Chesapeake, VA: AACE.

Papert, S. (1992). The children's machine. NY: Basic Books.

Papert, S. (1999). Logo philosophy and implementation. Montreal, QC: Logo Computer Systems Inc.

Richards, D. (2009). Designing project-based courses with a focus on group formation and assessment. ACM Transactions on Computing Education (TOCE), 9(1). 
Schwille, J., Dembélé, M., \& Schubert, J. (2007). Global perspectives on teacher learningImproving policy and practice. Fundamentals of Educational Planning, 84. Paris: UNESCO

Siemens, G. (2005). A learning theory for the digital age. Instructional Technology and Distance Education, 2(1), 3-10.

Sprague, D. (2006). Research agenda for online teacher professional development. Journal of Technology \& Teacher Education, 14(4), 657-661.

Stager, G. (2009). A constructionist approach to robotics. Paper presented at the 9th IFIP World Conference on Computers in Education, Bento Gonçalves, Brazil.

Toledo, C. (2007). Setting the stage to use blogging as a reflective tool in teacher education. In R. Carlsen et al. (Eds.), Proceedings of the Society for Information Technology \& Teacher Education International Conference 2007 (pp. 2111-2113). Chesapeake, VA: AACE.

Vrasidas, C., \& Glass, G. V. (Eds.). (2004). Online professional development for teachers. Greenwich, CO: Information Age Publishing.

Wang, F., \& Hannafin, M. (2003). Importance of design-based research for technologyenhanced learning environments. Educational Technology Research and Development, 53(4), 5-23.

Whitehouse, P. (2010). Networked teacher professional development: The case of Globaloria. Journal of Interactive Learning Research, 21(4).

Whitehouse, P., Breit, L., McCloskey, E., Ketelhut, D. J., \& Dede, C. (2006). An overview of current findings from empirical research on online teacher professional development. In C. Dede (Ed.), Online professional development for teachers: Emerging models and methods (pp. 13-30). Cambridge, MA: Harvard Education Press.

Whitehouse, P., Reynolds, R., \& Caperton, I. (2009). Globaloria pilot year one: New directions for 21st-century teacher professional development. In I. Gibson et al. (Eds.), Proceedings of the Society for Information Technology \& Teacher Education International Conference 2009 (pp. 1590-1597). Chesapeake, VA: AACE.

\section{Athabasca University $\mathbf{Z}$}

